\title{
BALANCE PATRIÓTICO*
}

\author{
Vicente Huidobro
}

Un país que apenas a los cien años de vida está viejo y carcomido, lleno de tumores y de supuraciones de cáncer como un pueblo que hubiera vivido dos mil años y se hubiera desangrado en heroísmos y conquistas.

Todos los inconvenientes de un pasado glorioso pero sin la gloria. No hay derecho para llegar a la decadencia sin haber tenido apogeo. Un país que se muere de senectud y todavía en pañales es algo absurdo, es un contrasentido, algo así como un niño atacado de arterioesclerosis a los once años.

El sesenta por ciento de la raza, sifilítica. El noventa por ciento, heredo-alcohólicos (son datos estadísticos precisos); el resto insulsos y miserables a fuerza de vivir entre la estupidez y las miserias. Sin entusiasmo, sin fe, sin esperanzas. Un pueblo de envidiosos, sordos y pálidos calumniadores, un pueblo que resume todo su anhelo de superación en cortar las alas a los que quieren elevarse y pasar una plancha de lavandera sobre el espíritu de todo aquel que desnivela el medio estrecho y embrutecido.

En Chile cuando un hombre carga algo en los sesos y quiere salvarse de la muerte, tiene que huir a países más propicios llevando su obra en los brazos como la Virgen llevaba a Jesús huyendo hacia Egipto. El odio a la superioridad se ha sublimado aquí hasta el paroxismo. Cada ciudadano es un Herodes que quisiera matar en ciernes la luz que se levante. Frente a tres o cuatro hombres de talento que posee la República, hay tres millones setecientos mil Herodes.

Y luego la desconfianza, esa desconfianza del idiota y del ignorante que no sabe distinguir si le hablan en serio o si le toman el pelo. La desconfianza que es una defensa orgánica, la defensa inconsciente del cretino que no quiere pasar por tal y cree que sonriendo podría enmascarar su cretinismo, como si la mirada del hombre sagaz no atravesara su sonrisa mejor que un reflector.

El huaso macuco disfrazado de médico que al descubrirse la teoría microbiana exclama: a mí no me meten el dedo en la boca; el huaso macuco disfrazado de artista o de político que cree que diciendo: no comprendo, mata a alguien en vez de hacer el mayor elogio.

Por eso Chile no ha tenido grandes hombres, ni podrá tenerlos en muchos siglos. ¿Qué sabios ha tenido Chile? ¿Qué teoría científica se debe a un chileno? ¿Qué teoría filosófica ha nacido en Chile? ¿Qué principio químico ha sido descubierto en Chile? ¿Qué político chileno ha tenido trascendencia universal? ¿Qué producto de fabricación chilena o qué producto del alma chilena se ha impuesto en el mundo? * El presente texto se conserva íntegro, atendiendo a la gramática y ortografía del original. Véase: Huido-
bro, Vicente, "Balance Patriótico", en Acción, año I (número 4), 8 de agosto de 1925. (N. del E.) 
No recuerdo nunca en una universidad de Europa, ni en Francia, ni Alemania; ni en ningún otro país haber oído el nombre de un chileno, ni haberlo leído en ningún texto.

Esto somos y no otra cosa. Es preciso que se diga de una vez por todas la verdad, es preciso que no vivamos sobre mentiras, ni falsas ilusiones. Es un deber, porque sólo sintiendo palpitar la herida podremos corregirnos y salvarnos aún a tiempo y mañana podremos tener hombres y no hombrinos.

Decir la verdad significa amar a su pueblo y creer que aún puede levantársele y yo adoro a Chile, amo a mi patria desesperadamente, como se ama a una madre que agoniza.

Recorred nuestros paseos, mirad las estatuas de nuestros hombres de pensamiento: ¡qué cisos (sic) de valores efectivos! A la excepción de 4 ó 5, ninguno de ellos habría sabido responder en un examen universitario de hombres serios iqué sabios de aldea, qué cerebros más primarios!

¿En dónde fuera de aquí iban a tener estatuas esos pobrecitos?

Es necesario levantar estatuas en los paseos y como no hay a quién elevárselas, el pueblo busca el primero que pilla, y cuando es el pueblo el que levanta monumentos, ellos surgen debido a las influencias de familias, son los hijos que levantan monumento al papá en agradecimiento por haberlos echado al mundo. ¡Es conmovedor!

¿Y el mérito, en dónde está el mérito? El pueblo pasa soñoliento y lánguido, arrastrando su cuerpo como un saco de pestes, su cuerpo gastado por la mala alimentación y carcomido de miserias y entre tanto la sombra de Francisco Bilbao llora de vergüenza en un rincón. ¿Qué hombre ha sabido sintetizar el alma nacional?

¡Pobre país; hermosa rapiña para los fuertes!

Y así vienen, así se dejan caer sobre nosotros; las inmensas riquezas de nuestro suelo son disputadas a pedazos por las casas extranjeras y ellos viendo la indolencia y la imbecilidad troglodita de los pobladores del país, se sienten amos y les tratan como a lacayos, cuando no como a bestias. Ellos fijan los precios de nuestra materia prima al salir del país y luego nos fijan otra vez los precios de esa misma materia prima al volver al país elaborada. Y como si esto fuera poco, ellos fijan el valor cotidiano de nuestra moneda.

Vengan los cuervos. Chile es un gran panizo. A la chuña, señores, corred todos, que todavía quedan migajas sobre la mesa.

¡Es algo que da náuseas!

Chile aparece como un inmenso caballo muerto, tendido en las laderas de los Andes bajo un gran revuelo de cuervos.

El poeta inglés pudo decir: "Algo huele a podrido en Dinamarca", pero nosotros, más desgraciados que él, nos veremos obligados a decir: "Todo huele a podrido en Chile".

Un gran banquero alemán decía en una ocasión a un ex encargado de negocios de Chile en Austria: "Los políticos chilenos se cotizan como las papas", y un magnate de las finanzas francesas decía otra vez, y esto lo oí yo: "Desde que a los políticos argentinos les dio por ponerse honrados, el gran panizo para los negocios es Chile".

Y esos prohombres de la política chilena, esos señores que entregarían el país maniatado por una sonrisa de Lord Curzon y unos billetes de Guggenheim, no se dan cuenta que cada vez que esos hombres les dan la mano, les escupen el rostro.

¡Qué desprecio deben sentir los señores del cobre por sus abogados! 
¡Qué asco debe sentir en el fondo de su alma el amo de nuestras fuerzas eléctricas por los patrióticos tinterillos que defienden sus intereses en desmedro de los intereses del país!

Y no es culpa del extranjero que viene a negocios en nuestra tierra. Se compra lo que se vende; en un país en donde se vende conciencias, se compra conciencias. La vergüenza es para el país. El oprobio es para el vendido, no para el comprador.

Frente a la antigua oligarquía chilena, que cometió muchos errores, pero que no se vendía, se levanta hoy una nueva aristocracia de la banca, sin patriotismo, que todo lo cotiza en pesos y para la cual la política vale tanto cuanto sonante pueda sacarse de ella. Ni la una ni la otra de estas dos aristocracias ha producido grandes hombres, pero la primera, la de los apellidos vinosos, no llegó nunca a la impudicia de esta obra de los apellidos bancosos.

La historia financiera de Chile se resume en la biografía de unos cuantos señores que asaltaban el erario nacional, como Pancho Falcato asaltaba las casas de una hacienda. Pero aquéllos más cobardes que éste, porque el célebre bandido por lo menos exponía su pellejo.

¡Pobre Chile! Un país que ha tenido por toda industria el aceite de Santa Filomena y los dulces de la Antonia Tapia. (Chile tiene hierro, Chile entero es un gran bloque de hierro y no posee Altos Hornos. La Argentina no tiene hierro y tiene Altos Hornos).

¿Y la Justicia?

La Justicia de Chile haría reír, si no hiciera llorar. Una Justicia que lleva en un platillo de la balanza la verdad y en el otro platillo, un queso. La balanza inclinada del lado del queso.

Nuestra Justicia es un absceso putrefacto que empesta el aire y hace la atmósfera irrespirable. Dura o inflexible para los de abajo, blanda y sonriente con los de arriba. Nuestra Justicia está podrida y hay que barrerla en masa. Judas sentado en el tribunal después de la crucificación, acariciando en su bolsillo las treinta monedas de su infamia, mientras interroga a un ladrón de gallinas.

Una Justicia tuerta. El ojo que mira a los grandes de la tierra, sellado, lacrado por un peso fuerte y sólo abierto el otro, el que se dirige a los pequeños, a los débiles.

Buscáis a los agitadores en el pueblo. No, mil veces no; el más grande agitador del pueblo es la Injusticia, eres tú mismo que andas buscando a los agitadores de abajo y olvidas a los de arriba.

Las instituciones, las leyes, acaso no sean malas, pero nunca hemos tenido hombres, nunca hemos tenido un alma, nos ha faltado el Hombre.

El pueblo lo siente, lo presiente y se descorazona, se desalienta, ya no tiene energías ni para irritarse, se muere automáticamente como un carro cargado de muertos que sigue rodando por el impulso adquirido.

Hace días he visto al pueblo agrupado en torno a la estatua de O'Higgins. ¿Qué hacían esos hombres al pie del monumento? ¿Qué esperaban? ¿Buscaban acaso protección a la sombra del gran patriota?

Tal vez creían ellos que el alma del Libertador flotaba en el aire y que de repente iba a reencarnarse en el bronce de su estatua y saltando desde lo alto del pedestal se lanzaría 
al galope por calles y avenidas, dando golpes de mandoble hasta romper su espada de tanto cortar cabezas de sinvergüenzas y miserables.

No valía la pena haberos libertado para que arrastrarais de este modo mi vieja patria, gritaría el Libertador.

Y luego, como una trompeta, exclamara a los cuatro vientos: despiértate, raza podrida, pueblo satisfecho en tu insignificancia, contento acaso de ser un mendigo harapiento del sol, resignado como un Job que lame su lepra en un establo.

Los países vecinos pasan en el tren del progreso hacia días de apogeo y de gloria. El Brasil, la Argentina, el Uruguay ya se nos pierden de vista y nosotros nos quedamos parados en la estación mirando avergonzados el convoy que se aleja. Hasta el Perú hoy es ya igual a nosotros y en cinco años más, en manos del dictador Leguía, nos dejará también atrás, como nos dejará Colombia, que se está llenando de inmigrantes europeos.

¿Y esto debido a qué? Debido a la inercia, a la poltronería, a la mediocridad de nuestros políticos, al desorden de nuestra administración, a la chuña de migajas y, sobre todo, a la falta de un alma que oriente y que dirija.

Un Congreso que era la feria sin pudicia de la imbecilidad. Un Congreso para hacer onces buenas y discursos malos.

Un municipio del cual sólo podemos decir que a veces poco ha faltado para que un municipal se llevara en la noche la puerta de la Municipalidad y la cambiase por la puerta de su casa. Si no empeñaron el reloj de la Intendencia y la estatua de San Martín, es porque en las agencias pasan poco por artefactos desmesurados.

¿Hasta cuándo, señores? ¿Hasta cuándo?

Es inútil hablar, es inútil creer que podemos hacer algo grande mientras no se sacuda todo el peso muerto de esos viejos políticos embarazados de palabras ñoñas y de frases hechas.

Al día siguiente del 23 de enero, cuando el país estaba sobre un volcán, isaben ustedes en qué se entretenía una de las lumbreras de nuestra vieja politiquería, a quienes preguntaban los militares qué opinaban sobre la designación de don Emilio Bello para ponerle al frente del Gobierno? En dar una conferencia de dos horas para probar que el nombramiento de don Emilio Bello era razonable, pues este caballero había sido Ministro de Relaciones cuando el General Altamirano era Ministro del Interior; por lo tanto, pasando el Ministro del Interior a la Jefatura del país, al Ministro de Relaciones le tocaba pasar al Interior, automáticamente, según las leyes, a la Vicepresidencia de la República, en caso de quedar vacante la Presidencia, y por lo tanto..., etc.

No se le ocurrió por un momento hablar de la competencia ni de la energía, ni de los méritos o defectos del señor Bello. El pobre hombre estaba buscando argucias justificativas cuando se trataba de obrar rápidamente, hipnotizado por las palabras cuando había que saltar por encima de todo. Pobre atleta enredado en la madeja de lanas de una abuela cegatona, en los momentos en que la casa está ardiendo.

He ahí el símbolo de nuestros políticos. Siempre dando golpes a los lados, jamás apuntando el martillazo en medio del clavo. Cuando se necesita una política realista y de acción, esos señores siguen nadando sobre las olas de sus verbosidades. 
Por eso es que toda nuestra insignificancia se resuelve en una sola palabra: Falta de alma.

¡Crisis de hombres! ¡Crisis de hombres! ¡Crisis de Hombre!

Porque, como dice Guerra Junqueiro, una nación no es una tienda, ni un presupuesto una Biblia. De la mera comunión de vientres no resulta una patria, resulta una piara. Socios no es lo mismo que ciudadanos. Al hablar de Italia decimos: la Italia del Dante, la Italia de Garibaldi, no la Italia de Castagneto, y es que el espíritu cuenta y cuenta por sobre todas las cosas, pues sólo el espíritu eleva el nivel de una nación y de sus compatriotas.

Se dice la Francia de Voltaire, de Luis XIV, de Víctor Hugo, la Francia de Pasteur; nadie dice la Francia de Citroen, ni de monsieur Cheron. Nadie dice la España de Pinillos, sino la España de Cervantes. Y Napoleón sólo vale más que toda la historia de la Córcega; como Cristóbal Colón vale más que toda la historia de Génova.

El mundo ignorará siempre el nombre de los pequeños politiquillos y comerciantes que vivieron en la época de los grandes hombres. Sólo aquellos que lograron representar el alma nacional llegaron hasta nosotros; de Grecia guardamos en nuestro corazón el nombre de Platón y de Pericles, pero no sabemos quiénes eran sus proveedores de ropa y alimentos.

En Chile necesitamos un alma, necesitamos un hombre en cuya garganta vengan a condensarse los clamores de tres millones y medio de hombres, en cuyo brazo vengan a condensarse las energías de todo un pueblo y cuyo corazón tome desde Tacna hasta el Cabo de Hornos el ritmo de todos los corazones del país.

Y que este hombre sepa defendernos del extranjero y de nosotros mismos.

Tenemos fama de imperialistas y todo el mundo nos mete el dedo en la boca hasta la campanilla. Nos quitan la Patagonia, la Puna de Atacama, firmamos el Tratado de Ancón, el más idiota de los tratados, y nos llaman imperialistas.

Advirtiendo de pasada que hubo un ministro de Chile en Argentina, el ministro Lastarria, que tuvo arreglado el asunto de la Patagonia, dejando a la Argentina como límite sur el Río Negro, y este ministro fue retirado de su puesto por antipatriota. Tal ha sido siempre la visión de nuestros gobernantes. Los huasos macucos tan maliciosos y tan diablos y sobre todo tan boquiabiertos.

Necesitamos lo que nunca hemos tenido, un alma. Basta repasar nuestra historia. Necesitamos un alma y un ariete, diré parafraseando al poeta íbero.

Un ariete para destruir y un alma para construir.

El descontento era tan grande, la corrupción tan general, que dos revoluciones militares estallaron al fin: la del 5 de septiembre de 1924 y la del 23 de enero de 1925.

La primera giraba a todos los vientos como veleta loca, para caer luego en el mismo desorden y en la misma corrupción que atacara en el Gobierno derrocado, echando sobre las espaldas de un solo hombre culpas que eran de todos; pero más que de nadie, de aquellos que, en vez de ayudarle, amontonaban los obstáculos en su camino. La segunda, hecha por un grupo de verdaderos idealistas, se diría que principia a desflecarse y a perder sus rumbos iniciales al solo contacto de la eterna lepra del país, los políticos viejos. 
¿Hasta cuándo tendrán la ingenuidad de creer que esa gente va a enmendarse y cambiar de un solo golpe sus manías del pasado, arraigadas hasta el fondo de las entrañas, como quien se cambia un paletó?

Dos revoluciones llenas de buenos propósitos, pero escamoteadas por los prestidigitadores de la vieja politiquería, de esa vieja politiquería incorregible y con la cual no hay que contar sino para barrerla.

El país no tiene más confianza en los viejos, no queremos nada con ellos. Entre ellos, el que no se ha vendido, está esperando que lo compren. Y no contentos con tener las manos en el bolsillo de la nación, no han faltado gobernantes que emplearán a costillas del Fisco a más de alguna de sus conquistas amorosas, pagando con dineros del país sus ratos de placer. ¿Y éstos son los que se atreven a hablar de patriotismo? Roban, corrompen las administraciones y, como si esto fuera poco, convierten al Estado en un cabrón de casa pública.

¿Qué se puede esperar de un país en el cual al más grande de los ladrones, al que comete la más gorda de las estafas, se le llama admirativamente: igallo padre!? Este es un peine, dicen, y lo dejan pasar sin escupirle el rostro.

Se dice que el robo lo tenemos en la sangre, que es herencia araucana. Bonita disculpa de francachela. Pues bien, si lo tenemos en la sangre, quiere decir que hay que extirparlo cortando cabezas. Por ahí sale la sangre. Si no hay más remedio, que salga como un río.

¡Qué mueran ellos, pero no muera el país!

Que suban al arca unos cuantos Noé y los demás perezcan en el diluvio de la sangre pútrida.

Como la suma de latrocinios de los viejos políticos es ya inconmesurable, que se vayan, que se retiren. Nadie quiere saber más de ellos. Es lo menos que se les puede pedir.

Entre la vieja y la nueva generación, la lucha va a empeñarse sin cuartel. Entre los hombres de ayer sin más ideales que el vientre y el bolsillo, y la juventud que se levanta pidiendo a gritos un Chile nuevo y grande, no hay tregua posible.

Que los viejos se vayan a sus casas, no quieran que un día los jóvenes los echen al cementerio.

Todo lo grande que se ha hecho en América y sobre todo en Chile, lo han hecho los jóvenes. Así es que pueden reírse de la juventud. Bolívar actuó a los 29 años. Carrera, a los 22; O'Higgins, a los 34, y Portales, a los 36.

Que se vayan los viejos y que venga juventud limpia y fuerte, con los ojos iluminados de entusiasmo y de esperanza.

8 de agosto de 1925. 